\title{
Erratum: GaAs nanopillar-array solar cells employing in situ surface passivation
}

\author{
Giacomo Mariani, Adam C. Scofield, Chung-Hong Hung \& Diana L. Huffaker
}

Nature Communications 4:1497 doi: 10.1038/ncomms2509 (2013); Published 19 Feb 2013; Updated 4 Jul 2013

The labels for the $x$ axis and optical absorption scale bar in Fig. 1c of this Article were inadvertently displaced during the production process. The correct version of Fig. 1 appears below.

a
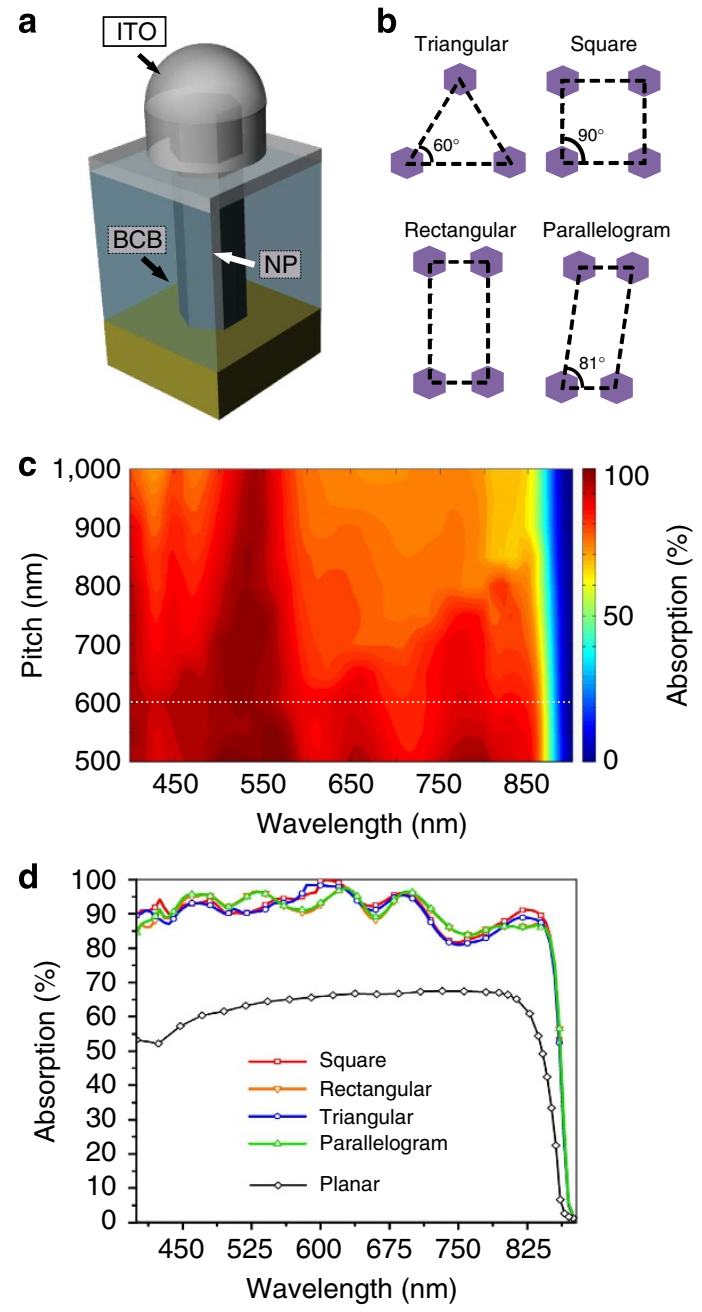

b

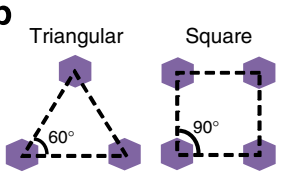

Rectangular Parallelogram

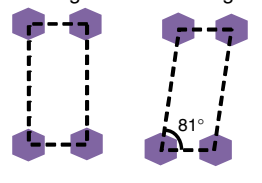

